\title{
Salvaguardas da Redd: proteção para as comunidades da Caatinga em Pernambuco, Brasil
}

\author{
Redd safeguards: protection for Caatinga communities in \\ Pernambuco state, Brazil
}

\author{
Afonso Feitosa Reis Neto \\ Maria do Socorro Bezerra de Araújo ${ }^{b}$ \\ Everardo Valadares de Sá Barreto Sampaioc
}

${ }^{a}$ Doutorando em Desenvolvimento e Meio Ambiente, Universidade Federal de Pernambuco, Recife, PE, Brasil. End. Eletrônico:afonso.reis@ifpi.edu.br

${ }^{b}$ Professora Associada III da Universidade Federal de Pernambuco (UFPE), Universidade Federal de Pernambuco, Recife, PE, Brasil. End. Eletrônico: soccorro@ufpe.br

'Professor Titular da Universidade Federal de Pernambuco (UFPE), Recife, PE, Brasil. End. Eletrônico: esampaio@ufpe.br

doi:10.18472/SustDeb.v10n1.2019.18927

Recebido: 08/11/2018

Aceito:21/03/2019

ARTIGO - VARIA

\section{RESUMO}

A Redução do Desmatamento e da Degradação Florestal (Redd) é um instrumento jurídico criado pelas Nações Unidas para combater o desmatamento dos remanescentes florestais nativos.Para sua plena efetividade, faz-se necessário o cumprimento de salvaguardas que possuem como objetivo proteger as comunidades receptoras dos projetos de conservação. Apesar da lacuna legal na esfera federal, Pernambuco disciplinou o instrumento na Lei Estadual no 15.809/2016, traçando seus próprios critérios de implementação. O interesse na efetivação deve-seao intenso processo de degradação do seu bioma predominante: a Caatinga. O bioma possui apenas $50 \%$ da sua cobertura vegetal original. Assim, o presente estudo buscou examinar as salvaguardas propostas para implementação da Redd na Caatinga de Pernambuco. Para tanto, as salvaguardas foram examinadas com base na metodologia ReddSafeguard Spectrum Framework (RSS Framework). Os resultados demonstram queas salvaguardas definidas possuem, em grande parte, um caráter abstrato, baseado em princípios gerais, dificultando seu monitoramento e aplicação.

Palavras-chave: Lei Estadual no 15.809/2016; RSS Framework; Salvaguardas na Redd.

\section{ABSTRACT}

Reducing Deforestation and Forest Degradation (Redd) is a legal instrument created by the United Nations to prevent deforestation of the remaining native forests. The enforcement of safeguards that aim to protect communities receiving conservation projects is necessary to attain its full effectiveness. Pernambuco state defined the instrument through its Act no 15.809/2016, outlining its own implementation criteria, in the absence of federal regulation. The state interest in the effectiveness is due to the intense process of degradation of its predominant biome: Caatinga. The biome has only 50\% of its native vegetation cover. Thus, the study examines the proposed safeguards for Redd implementation in the Caatinga of 
Pernambuco. For this purpose, the safeguards were examined following the Redd Safeguard Spectrum Framework (RSS Framework) methodology. The results demonstrate that the defined safeguards are largely abstract, based on general principles, making their implementation and monitoring difficult.

Keywords: State Act no 15.809/2016;Redd Safeguard Spectrum Framework; Redd Safeguards.

\section{INTRODUÇÃO}

O mecanismo de Redução de Emissões por Desmatamento e Degradação florestal (Redd) é uma modalidade de pagamentos por serviços ambientais, baseada no princípio do protetor-recebedor, que apresenta uma compensação pelo desmatamento evitado, remunerando indivíduos, comunidades, projetos e/ou países pelos benefícios de mitigação das mudanças climáticas trazidos pela manutenção de suas "florestas em pé" de vegetação nativa, que representam emissões evitadas de gases de efeito estufa, além de possibilitar aumento dos estoques de carbono (FURLAN, 2010).

A Redd inspira otimismo na política climática global capitaneada pela Organização das Nações Unidas (ONU). O Programa UN-Redd é considerado por muitos países, notadamente os de clima tropical e que ainda possuem florestas preservadas, o principal instrumento de enfrentamento dos crescentes índices de desmatamento (MATHEUS, 2018).

Apesar dos variados benefícios concebidos na teoria (manejo florestal, conservação dos estoques de carbono e participação das comunidades), são crescentes as evidências que apontam para uma complexidade de fatores envolvidos que impedem a plena efetividade de sua implementação, sendo esta alcançada "cuando logre cumplir a cabalidadel propósito por el cual fue creada"(CHACÓN, 2016, p.3). Problemas ligados à propriedade das terras, distribuição de renda, transparência nas informações, participação popular, definição de competências e respeito às salvaguardas ainda são recorrentes em diversos países (TONI, 2011).

A discussão é crucial não apenas para entender até que ponto a Redd cumpre ou não suas promessas, mas também para fornecer contribuições e lições dos próprios processos de concepção/implementação desse esquema. Tais percepções e as promessas do instrumento são ainda mais importantes no despertar dos Objetivos de Desenvolvimento Sustentável (ODS), recentemente acordados, que visam, entre outros objetivos, combater urgentemente as mudanças climáticas, enquanto manejam as florestas de forma sustentável e interrompem a degradação da terra juntamente com a perda de biodiversidade (DAWSON et al., 2018).

Essa preocupação com as florestas justifica-se pela sua importância na manutenção de serviços ambientais, a exemplo do ciclo da água e do estoque de carbono (REIS NETO et al., 2017). Ademais, a pressão antrópica é crescente nos mais diversos biomas. No estado de Pernambuco restam apenas $50 \%$ da vegetação original da Caatinga, sendo essa perda causada principalmente pela demanda energética da indústria, comércio e uso doméstico da população,e pela substituição por agricultura e pastagens (PERNAMBUCO, 2011).

A questão torna-se ainda mais delicada quando se leva em consideração as comunidades locais que dependem das florestas como fonte de combustível, alimento e medicamento. Acredita-se que as mudanças climáticas atingirão mais intensamente os mais pobres, e, portanto, a redução do desmatamento ajudará a construir a sua resiliência aos impactos climáticos (PARKER, 2009). Por esse fato, e também pela influência internacional, a importância não somente ambiental, mas social e econômica da manutenção da "floresta em pé" é fundamental e deve influenciar os rumos das decisões políticas sobre a Caatinga.

Posto esse quadro, o governo de Pernambuco, por meio da Lei Estadual no 15.809/2016, criou a sua Política Estadual de Pagamentos por Serviços Ambientais (Pepsa) em que a Redd é disciplinada, traçando limites para sua implementação, consubstanciados nas salvaguardas,edefinindo possíveis áreas receptoras (PERNAMBUCO, 2016). Nesse sentido, o presente artigo tem como objetivo examinar as salvaguardas propostas para implementação da Redd na Caatinga de Pernambuco. 


\section{REFERENCIAL TEÓRICO}

\subsection{SALVAGUARDAS: CONTEXTO GERAL}

Uma questão fundamental na implementação da Redd é a análise da situação preexistente de desigualdade entre pessoas que moram perto de florestas ou se utilizam de seus recursos florestais. A questão então é de que maneira as atuais ações reconhecem e procuram incluir elementos estruturais existentes de desigualdade como parte da criação de salvaguardas (PAMELA; PUSHPENDRA, 2017). Se não forem elaboradas com a devida atenção, os esforços da Redd podem, ainda que inadvertidamente, consolidar a desigualdade estrutural, oferecendo apenas benefícios simbólicos para as pessoas marginalizadas.

Entrar nesse instrumento significa, em termos práticos, participar de um acordo para canalizar mais recursos para os países em desenvolvimento ou projetos que implementam incentivos, políticas e financiamento para deter/reverter a perda e a degradação das florestas (MBATU, 2016). Realizado de maneira correta, oferece uma oportunidade apta para promover o manejo sustentável das florestas e reduzir as emissões relacionadas a esse setor.

Contudo, a concretização com viabilidade financeira e social das ações de Redd não vem sendo algo simples. Em muitos países, interesses puramente econômicos e a falta de diálogo entre os diversos atores tornam o ciclo de vida dos projetos muito curto, entrando em confronto direto com as disposições da Convenção-Quadro das Nações Unidas sobre Mudança do Clima (UNFCCC, sigla em inglês).

A menos que as iniciativas da Redd possam criar uma ponte entre esses diversos grupos e estabelecer benefícios para aqueles que mais precisam, elas simplesmente não funcionarão (NEUDERT, 2018). De fato, elas podem fazer mais mal do que bem, aprofundando a pobreza e a desconfiança, esgotando a biodiversidade e até mesmo aumentando as emissões relacionadas às florestas.

Os membros da UNFCCC reconhecem isso. Não por acaso, em 2010, eles assinaram as "Salvaguardas de Redd", que estabelecem sete princípios para governos e financiadores, na medida em que buscam programas para reduzir as emissões das paisagens florestais (UNFCCC, 2015). Projetadas no interesse de populações dependentes de florestas, elas incluem tomada de decisão transparente, participação de comunidades locais e a proteção de pessoas/ecossistemas vulneráveis.

O setor privado e a sociedade civil, com interesses distintos, vislumbraram, no instrumento, potencial para aumentar os recursos disponíveis para proteger os ecossistemas florestais e promover o desenvolvimento sustentável (ARHIN, 2014). Atores financiadores, como o Banco Mundial e a Aliança para o Clima, Comunidade e Biodiversidade (CCBA), também elaboraram, baseados no acordo de Cancún, suas salvaguardas que devem ser respeitadas para que os projetos submetidos à sua análise possam ser fomentados.

Os países/projetos que almejam a Redd e desejam receber pagamentos baseados no desempenho sob a UNFCCC são solicitados a fornecer resumos de informações sobre como as salvaguardas estão sendo "tratadas e respeitadas". Os países devem estabelecer sistemas de informações de salvaguarda para fornecer esses dados.

Esses requisitos apresentam desafios significativos para os interessados em aplicar a Redd, que precisarão interpretar as salvaguardas, determinar quais elementos coletar e como agregar essas informações de vários grupos de partes interessadas com orientação limitada da UNFCCC sobre como fazê-lo, enquanto também devem responder aos requisitos de salvaguarda dos seus acordos bilaterais e contratuais estabelecidos com os órgãos financiadores.

Muitos países ricos em florestas, a exemplo do Brasil, reconhecem essa realidade e estão começando a seguir esse caminho. Mas traduzir princípios de Direito Ambiental dos Acordos Internacionais, em prática, é algo complexo, principalmente quando a tradição do processo legislativo nacional (STRECK, 2012), além da própria aplicação das leis ambientais, esbarra em uma série de dificuldades que vão 
desde a ausência de discussão com a sociedade até a falta de recursos disponíveis para a execução, minando a efetividade e a eficácia (CHACÓN, 2016) das políticas ambientais.

Não obstante, o primeiro passo é entender efetivamente o que vem a ser uma salvaguarda. Para Daviet e Larsen (2012), o termo é empregado para referir-se às políticas e procedimentos utilizados por instituições financeiras para assegurar que os seus investimentos não causarão danos, sejam esses intencionais ou não. Essas políticas tradicionais de salvaguardas destinam-se a preencher lacunas onde as normas ou instituições nacionais não conseguem assegurar princípios de direitos humanos ou de proteção ambiental.

Por outro lado, Angelsen et al. (2012) definem as salvaguardas da Redd como um conjunto de normas e instituições que orientam expectativas em torno de resultados sociais e ambientais, associados à redução das emissões de carbono nos países em desenvolvimento. As salvaguardas representam um compromisso para garantir que os riscos sejam minimizados ou evitados, e que os benefícios sejam alcançados.

Sem a implementação completa das salvaguardas, os riscos são potencialmente altos para as pessoas, a biodiversidade e o sucesso como um mecanismo de mitigação climática e, portanto, sua implementação plena e efetiva é tão importante quanto a própriaRedd em si mesma (DAWSON et al., 2018). A comunicação abrangente e precisa em sua implementação é, nesse sentido, tão importante quanto o monitoramento e a emissão de relatórios sobre emissões de carbono florestal.

A transparência na implementação das salvaguardas é um fator-chave em qualquer projeto Redd. Em junho de 2015, o 42으rgão Subsidiário de Assessoramento Científico e Tecnológico (SBSTA 42) da UNFCCC decidiu que os países anfitriões da Redd devem fornecer informações sobre a implementação das salvaguardas de Cancún de forma a garantir os princípios de "transparência, consistência, abrangência e efetividade", além de reconhecer a "soberania nacional" (UNFCCC, 2015). Contudo, ainda é necessário que um instrumento prático, rigoroso e economicamente viável seja articulado.

Entender o impacto da Redd na governança, segurança da posse/propriedade do terreno, bem-estar social e outros indicadores é essencial para garantir que as políticas e programas sejam concebidos e implementados da maneira mais eficiente, efetiva e equitativa possível (DAWSON et al., 2018). Posto isso, o acompanhamento e os relatos dos países em desenvolvimento sobre as salvaguardas devem cobrir tanto as ações que geraram os resultados quanto as iniciativas que receberam financiamento proveniente de pagamentos por resultados.

Iniciativas com a chancela da UNFCCC preveem que os países em desenvolvimento que desejam obter pagamentos por resultados da Redd devem proporcionar meios para que as salvaguardas sejam acompanhadas de duas formas, no mínimo: (I) Elaboração de um sumário de salvaguardas; e (II) Sistema de Informações de Salvaguardas (UNFCCC, 2015). Segundo a definição do MMA (2015), o primeiro tem como objetivo oferecer informações sobre a implementação das salvaguardas de Cancún relativas ao resultado para o qual se pleiteiam pagamentos.

O documento, apresentado periodicamente, oferece uma fotografia da implementação das salvaguardas com foco no resultado da Redd, e é o requisito para acesso aos pagamentos. O segundo é um sistema, um verdadeiro repositório de dados, que, no caso brasileiro, se chamará Sisredd, que se encontra em fase de desenvolvimento e que deve propiciar o acompanhamento constante da implementação das salvaguardas pelo Brasil.

Cada país é obrigado a demonstrar a adequação exigida, desenvolvendo seu próprio sistema nacional de salvaguardas. A conformidade é informada por políticas, leis e regulamentos internos, e o relato ocorre por meio do que é chamado de Sistema de Informações de Salvaguardas. A própria UNFCCC não estipula qual a forma que os sistemas de salvaguarda devem tomar, apenas que as salvaguardas devem ser abordadas. 


\section{CONSIDERAÇÕES METODOLÓGICAS}

A metodologia usada como base para análise das disposições propostas na Lei Estadual no 15.809/2016 é a ReddSafeguard Spectrum Framework (RSS Framework), desenvolvida por Arhin (2014), em que cada salvaguarda é incorporada em um grupo de acordo com os seus objetivos propostos, conforme o Quadro 1.

Cabe destacar que a classificação composta originalmente por Arhin (2014) apresenta-senesta ordem: preventivesafeguards;mitigativesafeguards; promotivesafeguards; andtransformationalsafeguards. No entanto, no presente trabalho, foram adotadas apenas as três primeiras. A justificativa para tal escolha metodológica deve-seà particularidade da legislação ambiental brasileira e, por consequência,de Pernambuco, em razão da primazia aos princípios interpretativos.

O outro argumento que sustenta a não utilização integral da classificação original é a proximidade conceitual entre as promotivesafeguards e as transformationalsafeguards, já admitida pelo próprio autor. Apesar dos argumentos válidos de Arhin (2014), que residem principalmente na profundidade das modificações propostas pelas salvaguardas transformativas focadas de maneiras explícitas na participação popular, esta pesquisa, baseada em autores como Sarlet (2007) eStreck (2012), adotou a classificação de salvaguardas principiológicas para evidenciar um perigo existente em diversas normativas ambientais internacionais e principalmente brasileiras.

Quadro 1- Espectro de salvaguardas da Redd.

\begin{tabular}{|c|c|c|c|c|}
\hline Enquadramento & $\begin{array}{c}\text { Salvaguardas } \\
\text { Principiológicas }\end{array}$ & $\begin{array}{c}\text { Salvaguardas } \\
\text { Preventivas }\end{array}$ & $\begin{array}{c}\text { Salvaguardas } \\
\text { Mitigativas }\end{array}$ & $\begin{array}{c}\text { Salvaguardas } \\
\text { Impulsoras }\end{array}$ \\
\hline Objetivo Principal & $\begin{array}{c}\text { Buscar mudanças de } \\
\text { paradigmas nas } \\
\text { estruturas e marcos } \\
\text { legais. São princípios } \\
\text { gerais norteadores das } \\
\text { açốes. São } \\
\text { verdadeiras teses } \\
\text { programáticas. }\end{array}$ & $\begin{array}{l}\text { Prevenir pessoase } \\
\text { comunidades de } \\
\text { sofrerem danos } \\
\text { signifioativos em seus } \\
\text { meios de subsistência } \\
\text { devido às estratégias } \\
\text { adotadas para a Redd }\end{array}$ & $\begin{array}{c}\text { Mitigar os impactos } \\
\text { negativos da Redd } \\
\text { nas comunidades } \\
\text { locais e nos seus } \\
\text { meios de subsistência }\end{array}$ & $\begin{array}{c}\text { Promoverimelhorar } \\
\text { oportunidades para as } \\
\text { comunidades, } \\
\text { potencializando suas } \\
\text { práticas e os benefícios } \\
\text { ligados à Redd }\end{array}$ \\
\hline Como & $\begin{array}{c}\text { Definição de objetivos } \\
\text { para conduzit a } \\
\text { implementação e } \\
\text { gestăo da Redd. }\end{array}$ & $\begin{array}{c}\text { Evitando } \\
\text { estratégias/abordagens } \\
\text { com privaçö́es abusivas } \\
\text { para implantação da } \\
\text { Redd }\end{array}$ & $\begin{array}{l}\text { Amenização dos } \\
\text { impactos e das } \\
\text { consequências } \\
\text { negativas uma vez } \\
\text { ocorridos }\end{array}$ & $\begin{array}{c}\text { Afirmação dos direitos e } \\
\text { responsabilidades, em } \\
\text { vez de fazer mudanças } \\
\text { no regime sociopolitico } \\
\text { e normativo; } \\
\text { Implementação de } \\
\text { sistemas de } \\
\text { informaçốes sobre as } \\
\text { salvaguardas }\end{array}$ \\
\hline Exemplos & $\begin{array}{c}\text { Reduçăo da pobreza; } \\
\text { aumento da qualidade } \\
\text { de vida; Respeito aos } \\
\text { princípios da ONU. }\end{array}$ & $\begin{array}{c}\text { Evitar o despejo } \\
\text { forçado, a expulsấo das } \\
\text { terras, o deslocamento } \\
\text { e a esclusão de } \\
\text { comunidades looais do } \\
\text { uso de recursos, como } \\
\text { produtos florestais năo- } \\
\text { madeireiros. }\end{array}$ & $\begin{array}{l}\text { Reassentamento de } \\
\text { comunidades } \\
\text { deslooadas: } \\
\text { compensação às } \\
\text { comunidades e } \\
\text { indivíduos afetados: } \\
\text { garantia aos direitos } \\
\text { de uso dos produtos } \\
\text { não madeireiros. }\end{array}$ & $\begin{array}{l}\text { Incremento da } \\
\text { participação na } \\
\text { elaboraçấo de } \\
\text { políticas; fomentar a } \\
\text { responsabilidade e } \\
\text { transparência no } \\
\text { manejo florestal; } \\
\text { incentivar prátioas que } \\
\text { aumentem a difusão de } \\
\text { informaçóes. }\end{array}$ \\
\hline
\end{tabular}

Aumento da proteção e dos benefícios para as comunidades locais

Fonte: Elaborado pelo autor, baseado em Arhin (2014).

A criação dessa categoria tem como fundamento trazer à tona o uso em excesso de princípios na elaboração e aplicação das leis ambientais, gerando o denominado panprincipiologismo (STRECK, 2012). A utilização em excesso do referido instrumento hermenêutico pode causar situações, como a dificuldade de implementação do comando normativo no caso concreto e o perigo de abstração excessiva na interpretação da aplicação, trazendo como consequência a falta de efetividade (CHACÓN, 2016). 
Outra modificação realizada no RSS Framework original foi o reposicionamento das classes no espectro. Nesta, a classificação era disposta da seguinte maneira: preventive safeguards, mitigative safeguards, promotive safeguards and transformational safeguards. A desenvolvida para esta pesquisa pode ser visualizada no Quadro 1.

O motivo para tal alteração deve-se ao próprio contexto normativo da legislação ambiental do Brasil na qual existe uma grande primazia pelos princípios em detrimento de disposições concretas para aplicação. Baseado nessa justificativa, no espectro proposto, as salvaguardas mais à esquerda (que propiciam um menor aumento da proteção e benefícios à comunidade local) são as principiológicas e as mais à direita (que propiciam um maior aumento da proteção e benefícios à comunidade local) são as salvaguardas impulsoras.

Postas essas ressalvas, cabe conceituar cada categoria adotada de maneira mais analítica. As salvaguardas preventivas são aqueles critérios e proposições que buscam "não gerar dano" às comunidades locais. O objetivo principal, definido de maneira explícita ou não, é prevenir ou evitar a privação significativa como resultado da implementação da Redd (ARHIN, 2014). Exemplos de salvaguardas preventivas incluem o planejamento de estratégias específicas para Redd, evitando consequências, como a ocupação indireta, a desapropriação, a falta de terras (MATHEUS, 2018), o deslocamento e a exclusão de comunidades locais do uso de recursos (MBATU, 2016). Salvaguardas preventivas são os requisitos mínimos para estratégias de Redd.

As salvaguardas mitigativas são as iniciativas que buscam minimizar o impacto negativo daRedd sobre as comunidades locais e seus meios de subsistência (ARHIN, 2014). Enquanto as medidas preventivas reduzem a probabilidade de ocorrência do risco, as salvaguardas mitigativas reduzem o impacto se o risco ocorrer, como, por exemplo, o reassentamento de comunidades deslocadas, a compensação financeira de indivíduos afetados e a concessão de direitos para uso do espaço (NEUDERT, 2018), a exemplo do arrendamento e do usufruto.

Por fim, as salvaguardas impulsoras são aquelas cuja ênfase é amplamente voltada para a promoção ou melhoria de oportunidades, bem como espaços para as pessoas e comunidades florestais contribuírem para a tomada de decisões, melhorarem sua subsistência e beneficiarem-se do esquema Redd.

São consideradas catalisadoras dos benefícios alcançados. Exemplos podem incluir a promoção da participação de comunidades na formulação de políticas (ARHIN, 2014), o desenvolvimento de responsabilidade e transparência no manejo florestal, a instituição de práticas que aumentem a difusão de informações e a disponibilidade de assistência técnica para extensão rural (PAMELA; PUSHPENDRA, 2017).

Cabe destacar que uma mesma salvaguarda pode apresentar características diferentes.Ocorrendo tal hipótese, esta pode ser denominada salvaguarda mista ou híbrida. Por exemplo, é plenamente possível ter uma salvaguarda com traços das classes mitigativa e impulsora.

Via de regra, isso acontece na construção do texto no documento normativo e pode, sim, ser considerado um obstáculo para implementação da salvaguarda, tendo em vista que em vez de medir sua efetividade (CHACÓN, 2016) pela consecução de um objetivo (mitigativo ou impulsora, por exemplo), será necessária a obtenção nas duas frentes de atuação. Destarte, para fins tanto de construção quanto de análise ou implementação, o ideal é que as salvaguardas possuam traços preponderantes em uma das classes sugeridas.

Para classificação das dez (10) salvaguardas previstas na Pepsa, foi utilizada como base a revisão bibliográfica feita em periódicos, normas internacionais (Acordos e Tratados), legislação ambiental brasileira e guias de implementação de salvaguardas da ONU e do Banco Mundial. Com base na verificação, foi feito um quadro esquemático com a classificação das salvaguardas em que as linhas são as salvaguardas da Pepsa e as colunas a classificação proposta.

\section{RESULTADOS E DISCUSSÃO}

\subsection{SALVAGUARDAS REDD: PERNAMBUCO}

Com a criação daPepsa (Lei Estadual no 15.809/2016), Pernambuco criou seu marco legal para o desenvolvimento dos pagamentos por serviços ambientais (PSA), sendo pioneiro nessa temática na Região Nordeste. Entre as diversas modalidades de PSAsprevistas na legislação pernambucana, chama atenção a Redd (PERNAMBUCO, 2016). 
Apesar de suas discussões internacionais datarem do início do século XXI, ela ainda não tinha respaldo legal para sua implementação. Nessa perspectiva, em âmbito nacional, ainda existe uma lacuna normativa, que, contudo, não impediu que estados, como Acre, Amazonas e Pará (AMARANTE; RUIVO, 2013), além de Pernambuco, disciplinassem a matéria.

Com o objetivo de instrumentalizar a aplicação dos PSAs, a Pepsa trouxe em seu escopo uma lista de salvaguardas que devem ser observadas na composição dos projetos, inclusive a Redd. Essas salvaguardas podem ser observadas no Quadro 2.

Quadro 2-Salvaguardas da Pepsa

\begin{tabular}{|c|c|}
\hline \multicolumn{2}{|r|}{ SALVAGUARDAS DA PEPSA (Art. 4으) } \\
\hline I & reconhecimento e respeito acs diretos de posse e uso de terra, territórios e recursos naturais \\
\hline II & sustentabilicade eccnômica compativel com a melhoria de qualidade de vida eredução da pobreza \\
\hline III & $\begin{array}{l}\text { utilização racional dos recursos naturais através de técricas de manejo sustentável que assegurem a } \\
\text { proteção e integridade do sistema climático em beneficio das presentes e futuras geraçâes }\end{array}$ \\
\hline IV & $\begin{array}{l}\text { respeto acs conhecimentos ediretos dos povos e comunidades tradicionais e extrativistas, bem como aos } \\
\text { direitos humanos recornecidos eassumidos pelo Estado brasileiro perante a ONU e demais compromissos } \\
\text { intemacionais, incorporando-os às práticas de PSA, quandoc abivel }\end{array}$ \\
\hline v & $\begin{array}{l}\text { incorporação às iniciativas de PSA, sempre que possivel, de ações educ ativas, fornecimento de assistência } \\
\text { técrica e extensão rural, por meio de orientaçães e assessoria na elaboração, execução e/ou } \\
\text { monitoramerto de projetos de PSA }\end{array}$ \\
\hline VI & $\begin{array}{l}\text { justiça e equicdede na repartição dos benefícios econômicos e sociais oriundos dos produtos e serviços } \\
\text { vinculados aos pagamentos associados a esta Lei }\end{array}$ \\
\hline VII & $\begin{array}{l}\text { transparência, eficiência e efetividade na acministração dos recursos financeiros, com participação social } \\
\text { na sua aplicação, gestão e monitoramento }\end{array}$ \\
\hline VIII & $\begin{array}{l}\text { monituramento e transparência na elaboração, processos decisórios e implementação de iniciativas, } \\
\text { programas e prcjetos de PSA, garantindo-se disponibilidade plena de acesso às informações, participação } \\
\text { e cortrole social }\end{array}$ \\
\hline IX & $\begin{array}{l}\text { adoção do princípio do provedor-recebedor que defende a garartia de recompensa ao provedor de serviços } \\
\text { ambientais pela manutenção, recuperação ou melhoria desses serviços, apoiando-o na elaboração, } \\
\text { execução e/ou monitoramento de projetos técnicos }\end{array}$ \\
\hline $\mathrm{x}$ & 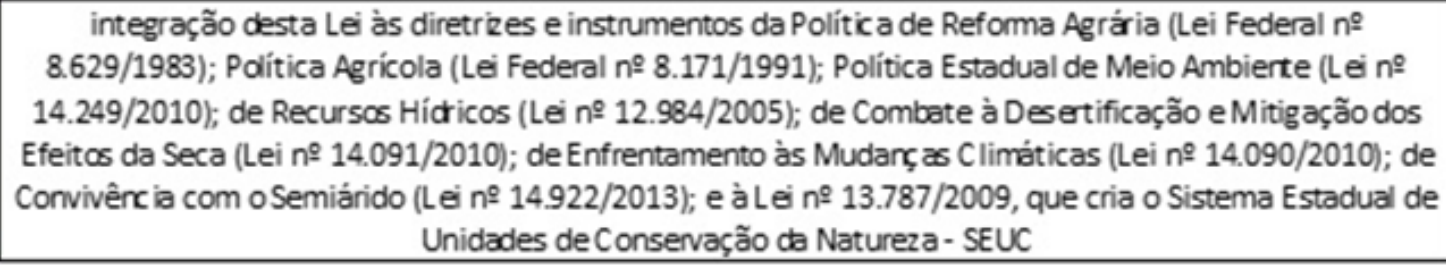 \\
\hline
\end{tabular}

Fonte: Elaborada pelo autor, com base em Pernambuco (2016).

Em uma breve leitura das salvaguardas, observa-se a preocupação com a simetria das proposições previstas nos Acordos Internacionais, principalmente as denominadas "Salvaguardas de Cancún". Conceitos de transparência, participação, direitos de posse e controle social são reiterados (PERNAMBUCO, 2016).

Contudo, cabe uma observação crítica que antecede até mesmo a disposição das salvaguardas na Pepsa. O texto do Art. 40 é bastante claro, não deixando grandes lacunas para explicação, e os incisos são autoexplicativos, ponto positivo que deve ser ressaltado. Contudo, a observação que deve ser feita reside no conteúdo de cada salvaguarda, que é o verdadeiro objetivo dessa análise. O espaço reservado na Pepsa poderia ser utilizado para elaboração de salvaguardas mais concretas, de caráter impulsor. O resultado da análise (Quadro 3), entretanto, mostra uma verdadeira preponderância de salvaguardas principiológicas. 
Quadro 3-Análise das Salvaguardas presentes na Pepsa pela metodologia RSS Framework

\begin{tabular}{|c|c|c|c|c|}
\hline $\begin{array}{c}\text { Art 40 da } \\
\text { PEPSA }\end{array}$ & $\begin{array}{c}\text { Salvaguardas } \\
\text { Principiológicas }\end{array}$ & $\begin{array}{c}\text { Salvaguardas } \\
\text { Preventivas }\end{array}$ & $\begin{array}{c}\text { Salvaguardas } \\
\text { Mitigativas }\end{array}$ & $\begin{array}{c}\text { Salvaguardas } \\
\text { Impulsoras }\end{array}$ \\
\hline I & & & & \\
\hline II & & & & \\
\hline III & & & & \\
\hline IV & & & & \\
\hline V & & & & \\
\hline VI & & & & \\
\hline VII & & & & \\
\hline VIII & & & & \\
\hline IX & & & & \\
\hline X & & & & \\
\hline \hline
\end{tabular}

Fonte: Elaborado pelo autor.

A crítica reverbera ainda mais quando se verifica que as salvaguardas principiológicas (em um total de quatro) trazem em seu conteúdo a mesma essência apresentada nas "Salvaguardas de Cancún". Mesmo as salvaguardas impulsoras, que são revestidas de maior concretude (ARHIN, 2014) na aplicação, carecem da explicitação do modo como serão monitoradas e efetivadas. Essa ausência não apenas se verifica no Art. 4으, mas em toda a Pepsa não fica claro o modo como as salvaguardas serão aplicadas e acompanhadas.

Cabe destacar que a análise identificou nas salvaguardas: quatro (4) principiológicas; duas (2) preventivas; uma (1) mitigativa; e quatro (4)impulsoras. Em relação à identificada como mitigativa, ela apresenta traços de impulsora. Por essa razão, é considerada uma salvaguarda mista/híbrida, sendo contabilizada nas duas classes. Os dados obtidos são um verdadeiro retrato da legislação ambiental brasileira, em que existe primazia pelos princípios e normas abertas.

De acordo com Streck (2012), essa utilização em excesso dos princípios faz com que esses sirvam apenas como "amarras interpretativas", esvaziando seu real valor. Os princípios devem ser entendidos por meio de seu caráter normativo, não podendo ter mero papel retórico-corretivo, tampouco ser entendidos como mandados de otimização, recheados de predicados.

Essa característica não é exclusiva da legislação ambiental. A enorme influência da teoria dos princípios na própria Constituição e mesmo nas sentenças do Supremo Tribunal Federal é algo autoevidente. Ferrajoli (2012) já havia alertado para a consequência dessa utilização em excesso:

[...] terminou se transformando, nestes últimos anos, em uma espécie de bolha terminológica, tão dilatada que chegou às formas mais variadas de esvaziamento e de inaplicação das normas constitucionais e infraconstitucionais, tanto no nível legislativo quanto no nível jurisdicional. (FERRAJOLI, 2012, p. 47)

Sundfeld (2012) chegou a afirmar que princípios em demasia são como "armas de espertos e de preguiçosos", ante a comodidade que oferecem aos legisladores e hermeneutas, na medida em que ocultam a fragilidade argumentativa de direitos invocados com base em princípios ocos de expressão normativa para determinados casos.

Nesse sentido, não é equivocado afirmar que o espaço dedicado às salvaguardas principiológicas poderia ser melhor utilizado com a previsão da obrigatoriedade da regularização fundiária das áreas que desejam implementar a Redd por parte do órgão financiador; a previsão expressa de umaouvidoria para eventuais problemas decorrentes do processo de implementação; a definição de indicadores de monitoramento das salvaguardas (renda da comunidade, acesso à educação e aumento da regeneração natural da área) e até mesmo um Sistema Estadual de Informações,no qual seriam compiladas 
desde informações de cunho financeiro (contratos, percentuais de emissões evitadas e dados dos fornecedores) até questões sociais.

Apesar dessas características, não há impedimento quanto à implementação da Redd, tornandose apenas mais complexo o processo de verificação no cumprimento dessas salvaguardas e, por conseguinte, a sua plena efetividade (CHACÓN, 2016). Por exemplo, de que maneira poderá ser verificado se está ocorrendo "a justiça e equidade na repartição dos benefícios".

De outra forma, as salvaguardas preventivas, apesar de serem apenas duas (2), estão bem exemplificadas pelo seu essencial que é o reconhecimento dos direitos das comunidades. Essa é uma salvaguarda que pode ser extraída de um dos sete princípios de Cancún;ademais,a Pepsa trouxeo texto de maneira mais clara e objetiva, facilitando a compreensão.

Em relação à salvaguarda mitigativa, cabe um alerta. Conforme dito anteriormente, ela possui como objetivo minimizar o impacto negativo da Redd sobre as comunidades locais e seus meios de subsistência (ARHIN, 2014). Trazer apenas uma (1) mitigativa é quase como assumir que não haverá problemas decorrentes da implementação a serem minimizados. Nesse sentido, seria salutar a previsão de compensações (financeiras ou por meio de projetos) para as comunidades, e de reassentamento de comunidades (total ou parcial) para melhor gerenciamento do instrumento,entre outros (NEUDERT, 2018).

Desse modo, apesar do Art.4을 da Pepsa apresentar lacunas que necessitam de um aperfeiçoamento, estas não chegam a inviabilizar a efetivação da Redd. Contudo, seria necessária a definição de alguma forma de controle e acompanhamento da aplicação, tendo em vista que assim seria possível avaliar "laexistencia de capacidad técnica, institucional y presupuesto suficiente para suefectivaaplicación"(CHACÓN, 2016, p.44).

\section{CONSIDERAÇÕES FINAIS}

A redução paulatina dos remanescentes florestais nativos vem chamando atenção dos diversos atores no cenário mundial, seja ligados a setores da sociedade civil, seja as instituições financeiras de fomento como o Banco Mundial. Essa discussão é incentivada pela UNFCCC na medida em que desenvolve um mecanismo jurídico denominadoRedd que possui como objetivo preservar áreas nativas por meio de compensação financeira aos países/projetos.

Com a delimitação dos principais requisitos para implementação, o instrumento começou a ser posto em prática acarretando uma série de críticas, principalmente de cunho social,consubstanciadas no desrespeito aos direitos (propriedade das terras e uso dos recursos) das comunidades que se utilizam dos remanescentes para sua subsistência. Buscando remediar o referido quadro, foram propostas salvaguardas para proteger as populações que são diretamente afetadas por essas iniciativas.

Apesar do seu protagonismo em relação às discussões climáticas, o Brasil ainda não disciplinou aRedd em sua legislação ambiental. Isso não impediu que os estados, a exemplo de Pernambuco, por meio da Lei Estadual no 15.809/2016, definissem requisitos e critérios para sua efetivação. Todavia, as salvaguardas propostas, em sua maioria, são baseadas em princípios gerais, o que dificulta a sua implementação.

Com base na metodologiaRSS Framework, a presente análise encontrou um grande número de salvaguardas principiológicas (4) e poucas salvaguardas mitigativas (1). Nesse sentido, a ação ideal seria a reformulação das salvaguardas propostas, principalmente a redução das principiológicas e o aumento das mitigativas. No entanto, a referida ação, em razão do processo legislativo, pode ser uma iniciativa de médio/longo prazo. Como medida mais imediata, a principal recomendação que pode ser feita é definir, por meio dos arranjos institucionais competentes, critérios objetivos para verificar o cumprimento das salvaguardas.

A definição de indicadores de monitoramento para as salvaguardas (renda da comunidade, acesso à educação e aumento da regeneração natural da área) e até mesmo um Sistema Estadual de Informações no qual seriam compiladas desde informações de cunho financeiro (contratos, percentuais de 
emissões evitadas e dados dos fornecedores) até questões sociais são proposições que podem facilitar o monitoramento do instrumento.

Sistemas bem projetados para implementar as salvaguardas deRedd podem melhorar as regras e instituições que governam o manejo florestal e construir a confiança entre as comunidades locais, o governo e os financiadores. Talvez o mais importante, eles podem ajudar a orientar os benefícios do desenvolvimento para as pessoas que utilizam os recursos florestais, especialmente as mais pobres.

\section{REFERÊNCIAS}

ANGELSEN, A.;BROCKHAUS, M.;SUNDERLIN, W.D.(Ed.). Analysing Redd+:challenges and choices. Bogor: CIFOR, 2012.

AMARANTE, C. B.; RUIVO, M. L. P. A política ambiental à luz da Convenção sobre Mudanças Climáticas: uma análise da implementação jurídiconormativa do Redd no Pará. In: NovosCadernosNaea, v.16, p.67-96, 2013.

ARHIN, A. A. Safeguards and dangerguards: aframework for unpacking the black box. In: Forest Policy and Economics, v. 45, p.24-31, 2014.

BRASIL. Ministério do Meio Ambiente. Redd + Relatório de painel técnico do MMA sobre financiamento, benefícios e cobenefícios. Brasília: MMA, 2015.

CHACÓN, M.P. El caminohacialaefectividaddelderecho ambiental.In:Innovare, v. 5, n.1, p.34-48, 2016.

DAVIET, F.; LA LARSEN, G. Safeguarding forest and people:aframework for designing a national system to implement Redd+ safeguards. Berna: World Resources Institute, 2012.

DAWSON, N.M. et al. Barriers to equity in Redd+: deficiencies in national interpretation processes constrain adaptation to context.In:Environmental Science and Policy, v.88, p.1-9, 2018.

FERRAJOLI, L. Constitucionalismo principialista e constitucionalismo garantista. In: FERRAJOLI, L.; STRECK, L. L.; TRINDADE, A. K. (Org.). Garantismo, hermenêutica e (neo)constitucionalismo: um debate com Luigi Ferrajoli. Porto Alegre: Livraria do Advogado, 2012.

FURLAN, M. Mudanças climáticas e valoração econômica da preservação ambiental:o pagamento por serviços ambientais e o princípio do protetor-recebedor.Curitiba: Juruá, 2010.

IRAWAN, S.; TACCONI, L. Reducing emissions from deforestation and forest degradation (Redd) and decentralized forest management. In:Forest, v.11, p.427-438, 2013.

MATHEUS, F.S. The role of forests and protected areas in climate change mitigation: a review and critique of the ecosystem services and Redd+ approaches. In: Desenvolvimento e MeioAmbiente, v.46, p.23-36, 2018.

MBATU, R. Redd+research: reviewing the literature, limitations and ways forward. In: Forest PolicyandEconomics, v.73, p.140-152, 2016.

NEUDERT, R.; OLSCHOFSKY, K.; KUBLER, D. Opportunity costs of conserving a dry tropical forest under Redd+: the case of the spiny dry forest in southwestern Madagascar. In: Forest Policy and Economics, v. 95, p.102-114, 2018.

PAMELA, J.; PUSHPENDRA, R.Using publicly available social and spatial data to evaluate progress on Redd+ social safeguards in Indonesia. In: Environmental Science and Policy, v.76, p.59-69, 2017.

PARKER, C. The Little Redd+ Book. Oxford: Global Canopy Foundation, 2009.

PERNAMBUCO. Lei Estadual 15.809/2016. Dispõe sobre Política Estadual de Pagamentos por Serviços Ambientais (Pepsa), e dá outras providências. Disponível em: <www.cprh.pe.gov.br/.../PEPSA>. Acesso em: 02 nov. 2018.

PERNAMBUCO. Plano Estadual de Mudanças Climáticas. Recife: Semas, 2011. 
REIS NETO, A.F.; SILVA, L.J.A.; ARAÚJO, M.S.B. Mata Atlântica pernambucana: argumentos jurídicos para implementação da Redd.In:Veredas do Direito, v.14, n.30, p.143-168, 2017.

SARLET, I. W. A eficácia dos direitos fundamentais. 9. ed. Porto Alegre: Livraria do Advogado, 2007.

STRECK, L. Do panprincipiologismo à concepção hipossuficiente de princípio: dilemas da crise do direito. In: Revista de Informação Legislativa, v.194, p.7-21, 2012.

SUNDFELD, C. A. Direito administrativo para céticos. São Paulo: Malheiros, 2012.

TONI, F. Decentralization and Redd+ in Brazil. In:Forest, v.2, p.66-85, 2011.

UNFCCC. The Cancun Agreements: outcome of the work of the Ad-Hoc working group on long-term cooperative action under the convention. Decisões 1/CP.16. Disponível em: <http://unfcc.int/resource/docs/2015/cop19/ eng/10a01.pdf\#page=24>. Acesso em: 02 nov. 2018. 